\title{
Residual stress research on Heavy Rail using X-ray diffraction and impact indentation method
}

\author{
Huan Xue ${ }^{1, a}$, Long Yan ${ }^{1}$, Rui Ge ${ }^{1}$, Yuxi Ma ${ }^{1}$, Wenjie Peng ${ }^{1}$ \\ ${ }^{1}$ Research and Development Center of Wuhan Iron and Steel group Corp., Wuhan, 430080, China \\ astonemechanics@163.com
}

Keywords: Residual stress, Heavy rail, U75V, X-ray diffraction, impact indentation.

\begin{abstract}
The residual stress distribution condition of homemade heavy rail U75V are tested by $\mathrm{X}$-ray and impact indentation method. Results shows the stress magnitude order from high to low of heavy rail is the same with two methods: Bottom center, Head middle, Bottom right, Head right, Waist. The relative error of indentation method is higher than the X-ray method. The residual stress on the bottom center of homemade rail is much higher than the import one, whereas the stress on the head center of homemade rail is lower than the import one. The compress residual stress exists on the waist position of both homemade and import heavy rail.
\end{abstract}

\section{Introduction}

The residual stress problem not only relates to daily necessities of civilians, but also runs on military field, or even national security. In many industrial productions, the residual stress problem is very prominent, including a variety of mechanical assembly processes such as extrusion, rolling, drawing, cutting, grinding, surface rolling, shot peening, hammering. The residual stresses can reduce the strength of components, or even bring defective workmanship such as cracking and deforming in manufacturing process [1-4]. On the other hand, after products are manufactured, the stress releasing deformation will change the size of the components or reduce their fatigue strength, stress corrosion and other mechanical performance, which is important to ensure the quality, safety and reliability of products.

The residual stress testing methods have two categories: mechanical methods and physical methods. Conventional mechanical determination of residual stress can by classified by the damage degree of components, including the completely stress release testing method and the partial stress release measuring method [5]. The typical methods such as fully cross section split, grooving, layer stripping method and hole drilling method are widely used. The advantages of such methods are the testing methods are brevity and clarity, and the corresponding theory has been very mature, in addition they experienced a lot of practical applications. However, their shortcomings are obvious: the testing process will damage the components and the processing cost is comparatively high. On the other side, the physical detecting methods include X-ray, ultrasonic and magnetic methods etc., whose advantages are that the nondestructive testing will produce no damage to the components [6]. The impact indentation method for residual stress determination is entirely different from the stress releasing testing method [7-9]. On the contrary, a new stress field is acted on the initial one, the residual stress is determined by measuring the material behavior change when the new stress field is introduced. Indentation method for residual stress determination has the advantage of simple mechanical operations. Only small stress is needed as a superposition under testing position, therefore the operation is much simpler, leading a fairly good adaptation in complex or large-volume testing conditions.

In this study, the X-ray and indentation method for residual stress testing are introduced. The residual stresses on five positions include Bottom center, Head middle, Bottom right, Head right, Waist, of 8 samples of homemade heavy rail U75V are tested by X-ray and indentation method in Section 2 and 3 . The residual stress results of homemade rail and import one with two testing methods are compared and analyzed in Section 4. 


\section{Residual stress of Heavy Rail tested by X-ray diffraction method}

XRD techniques are used to determine the distance between crystallographic planes, i.e. the d-spacing, and thus its application is limited to crystalline, polycrystalline and semi-crystalline materials. When a material is in tension, the d-spacing increases and when a material is in compression the d-spacing decreases. The presence of residual stresses in a material produces a shift in the x-ray diffraction peak angular position that is directly measured by the detector. For a known $\mathrm{x}$-ray wavelength $\lambda$ and $\mathrm{n}$ equal to unity, the diffraction angle $2 \theta$ is measured experimentally and the $\mathrm{d}$-spacing is then calculated using Bragg's law [10], and the residual stress can be calculated by:

$$
\sigma=-\frac{E}{2(1+v)} \cdot \frac{\pi}{180} \cdot \cot \theta_{0} \cdot \frac{\partial 2 \theta}{\partial \sin ^{2} \psi}
$$

Where $\sigma$ is the surface residual stress, $\mathrm{E}$ is elastic modulus, $v$ is Poisson's ratio, $\theta_{0}$ is the diffraction angle on stress free condition, $\Psi$ is the separation angle between surface normal line and selected crystal plane normal line, $\theta$ is the diffraction angle. Then

$$
M=\frac{\partial 2 \theta}{\partial \sin ^{2} \psi}, \quad K=-\frac{E}{2(1+v)} \cdot \frac{\pi}{180} \cdot \cot \theta_{0}
$$

While $\sigma=K \cdot M$, M is the slope of $2 \theta-\operatorname{Sin}^{2} \Psi$ curve, and $\mathrm{K}$ is the stress constant.

IXRD X-ray residual stress tester made by Proto is used to do validate test along length direction. The residual stress test process using X-ray method is according to national laboratory standards GB/T7704-2008 [10]. In this experiment, the round $\varphi 2 \mathrm{~mm}$ collimator is employed. As the sheet pile is ferritic steels, $\mathrm{C} \gamma \mathrm{K} \alpha$ radiation and vanadium foil filters is used. Diffraction crystal face is (211) with the stress constant $\mathrm{K}=-318 \mathrm{MPa} /\left(^{\circ}\right)$.

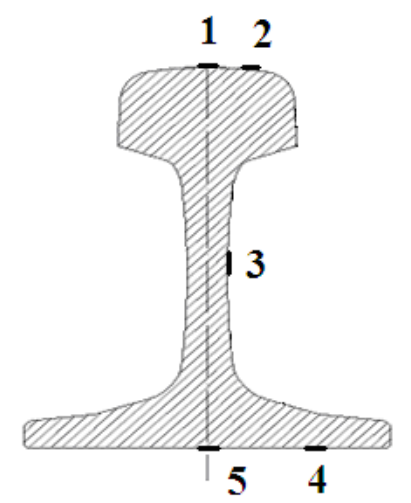

Figure 1 Test position on heavy rail

The residual stress of heavy rail U75V on head middle, head right, waist, bottom right, bottom center has been tested by X-ray method. The test position is shown in Figure 1. The test result is show in Table 1. The highest residual stress presents on the bottom center of heavy rail, which is around 220Mpa. So the residual stress risk on this position should be noticed. The second highest residual stress presents on the head middle position, which is around 150Mpa. The compress residual stress exists on the waist position of all the samples. The residual stress value tested by X-ray method represents nice compatibility.

Table 1 Residual stress tested by X-ray method (Mpa)

\begin{tabular}{|c|c|c|c|c|c|}
\hline Sample No. & $\begin{array}{c}1 \\
\text { Head middle }\end{array}$ & $\begin{array}{c}2 \\
\text { Head right }\end{array}$ & $\begin{array}{c}3 \\
\text { Waist }\end{array}$ & $\begin{array}{c}4 \\
\text { Bottom right }\end{array}$ & $\begin{array}{c}5 \\
\text { Bottom center }\end{array}$ \\
\hline $1 \#$ & 134 & 45 & -110 & 20 & 210 \\
\hline $2 \#$ & 115 & 4 & -114 & 11 & 255 \\
\hline $3 \#$ & 197 & -14 & -122 & 28 & 173 \\
\hline $4 \#$ & 147 & 45 & -132 & 29 & 229 \\
\hline $5 \#$ & 158 & -23 & -137 & 80 & 235 \\
\hline $6 \#$ & 170 & 48 & -140 & 23 & 219 \\
\hline $7 \#$ & 122 & 8 & -125 & 34 & 239 \\
\hline $8 \#$ & 129 & 46 & -131 & 107 & 234 \\
\hline
\end{tabular}




\section{Residual stress of Heavy Rail tested by impact indentation method}

The residual stress can be determined by measuring the strain increment in the indentation formatting process. The mechanical and mathematical model of this method can be established, which has strict scientific basis in theory. The absolute value of the indentation strain increment increases with tensile stress and strain increases. On the contrary, the compression stress makes the strain increment decreases. The linear relationship between residual stress and strain increment relates with the steel material, surface condition, ball diameter, the strain gage size, distance between strain gage and ball center, impact energy, static pressure and other factors.

The residual stress of $\mathrm{U} 75 \mathrm{~V}$ is tested by impact indentation method according to GB/T 24179-2009 [11]. The test position is the same with X-ray method. The highest residual stress is around $210 \mathrm{Mpa}$, presents also on the bottom center of heavy rail. The second highest residual stress is around 145Mpa, presents on the head middle position. The residual stress value tested by indentation method represents commonly compatibility.

Table 2 Residual stress tested by indentation method (Mpa)

\begin{tabular}{|c|c|c|c|c|c|}
\hline Sample No. & $\begin{array}{c}1 \\
\text { Head middle }\end{array}$ & $\begin{array}{c}2 \\
\text { Head right }\end{array}$ & $\begin{array}{c}3 \\
\text { Waist }\end{array}$ & $\begin{array}{c}4 \\
\text { Bottom right }\end{array}$ & $\begin{array}{c}5 \\
\text { Bottom center }\end{array}$ \\
\hline $1 \#$ & 152 & 48 & -140 & 8 & 201 \\
\hline $2 \#$ & 133 & 19 & -128 & 27 & 238 \\
\hline $3 \#$ & 177 & -29 & -101 & 45 & 197 \\
\hline $4 \#$ & 123 & 37 & -131 & 82 & 244 \\
\hline $5 \#$ & 179 & -32 & -127 & 121 & 193 \\
\hline $6 \#$ & 136 & 42 & -112 & 39 & 192 \\
\hline $7 \#$ & 152 & 12 & -144 & 12 & 217 \\
\hline $8 \#$ & 165 & 67 & -119 & 140 & 266 \\
\hline
\end{tabular}

\section{Results comparison}



Figure 2 Comparison between two testing method

The residual stress results comparison between X-ray method and impact indentation method is shown in Figure 2. It can be found that the stress magnitude order is the same with two methods: Bottom center, Head middle, Bottom right, Head right, Waist. However the relative error of indentation method is higher than the X-ray method. On the other hand, the residual stress distribution condition of homemade and import heavy rail is compared, shown in Figure 3. The residual stress value of import rail is from Ref [3]. It can be seen that the residual stress on the bottom center of homemade rail is around 220Mpa, which is much higher than the import one. Whereas the 
stress on the head center of homemade rail is lower than the import one. The compress residual stress, which is around $-120 \mathrm{Mpa}$, exists on the waist position of both homemade and import heavy rail.

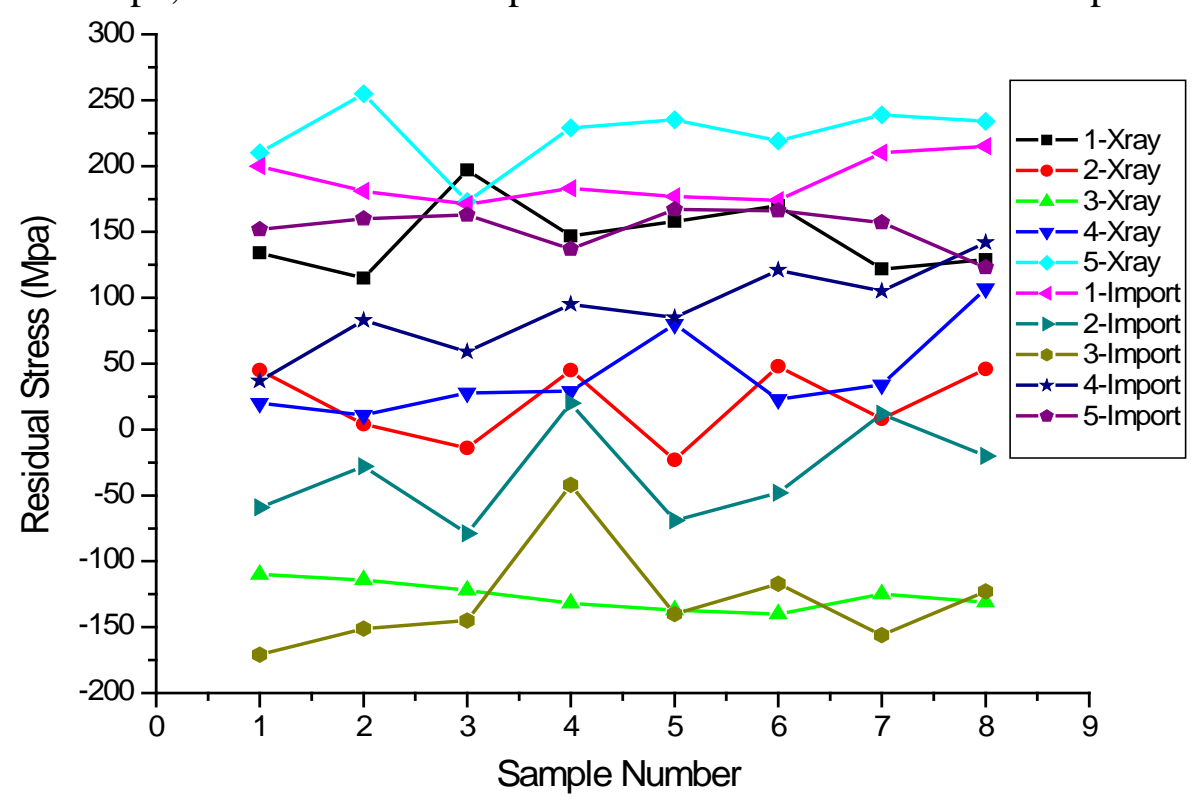

Figure 3 Comparison between homemade and import rail

\section{Conclusions}

(1) The X-ray and indentation method for residual stress testing are introduced.

(2) The stress magnitude order of heavy rail is the same with two methods: Bottom center, Head middle, Bottom right, Head right, Waist.

(3) The relative error of indentation method is higher than the X-ray method.

(4) The residual stress on the bottom center of homemade rail is much higher than the import one, whereas the stress on the head center of homemade rail is lower than the import one.

\section{References}

[1] J. W. He, K.B. Xu, J.B. Li: International Academic Developments, No. 4 (1998), p. 75

[2] G. Jiang, M.H. Tan, W. M. Wang, W. He: Machine Tool \& Hydraulics, Vol. 35, No. 6 (2007), p. 213

[3] X. W. Zhan and S.Q. Wang: Railway Quality Control, Vol. 37, (2009), p. 7

[4] S. H. Wang, D.W. Zuo, X.F. Li and M. Wang: Journal of Applied Sciences, Vol. 23, (2005), p.192

[5] Mather. J: Determination of Initial Stress by Measuring the Deformation Around Drilled Hole, Vol. 56, (1934), p. 245-254.

[6] C. Ding, B. G. Tang, S. B. Wang, X. M. Yue, W. R. LI, P. P. Wang: Journal of Zhengzhou Unibersity of Light Industry. 2005, 20(4): 68-70

[7] J. Frankel, A. Abbate and W. Scholz: Experimental Mechanics, (1993), p.164

[8] W.C. Oliver, G.M. Pharr: Journal of Materials Research. Vol. 7, No. 6 (1992), p. 1564

[9] C.S. Lu, Journal of Mechanical Strength: Vol. 14, (1992), p.29

[10] Chinese National Standard: Non-destructive testing- Practice for residual stress measurement by X-ray, GB/T 7704-2008.

[11] Chinese National Standard: Metallic materials-Residual stress determination-The indentation strain gage method, GB/T 24179-2009 